\title{
Extended methods of enteroscopy
}

Single balloon enteroscopy (SBE) allows direct visualization of the small bowel and is important in the evaluation of covert gastrointestinal bleeding. The complication rate for double balloon enteroscopy is $1 \%$. Complications include acute pancreatitis, perforation, and bleeding $[1,2]$. There are no published data of bacteremia following double balloon enteroscopy.

A 57-year-old gentleman was admitted with anemia and extensive hemochezia. History included hepatojejenostomy for biliary obstruction secondary to alcoholinduced chronic pancreatitis. He had noncirrhotic portal hypertension.

During his admission he required 39 units of blood. Identification of the bleeding source proved difficult despite esophagogastroduodenoscopy, colonoscopy, and video capsule endoscopy. Radiological imaging demonstrated varices at the hepaticojejunostomy anastomosis and porta hepatis (choledochal varices). The patient underwent SBE ( $\bullet$ Fig. 1 ). The procedure was uncomplicated and no abnormality was demonstrated. However, 24 hours later he developed clinically significant Streptococcus milleri bacteremia. Antiobiotic treatment was commenced and he made an uneventful recovery. No other potential source of the bacteremia was identified.

Humans and animals are hosts for Group $C$ and $G$ streptococci species. They are part of the normal skin, oral cavity, gastrointestinal, and vaginal flora. Patients infected with these streptococci typically include the elderly, men (who are more than twice as likely as women to become infected), and immunocompromised patients. Other risk factors include the postoperative period and animal product exposure [3].

Bacteremia of these phenotypes is associated with a mucosal breach. Identification is only possible through culture of pathognomic species [4]. Bacterial complications following endoscopic procedures are rare but may include liver or cerebral abscesses [5]. The incidence of these complications may increase, however, as current guidelines have removed antibiotic prophylaxis prior to procedures, even in high-risk individuals.

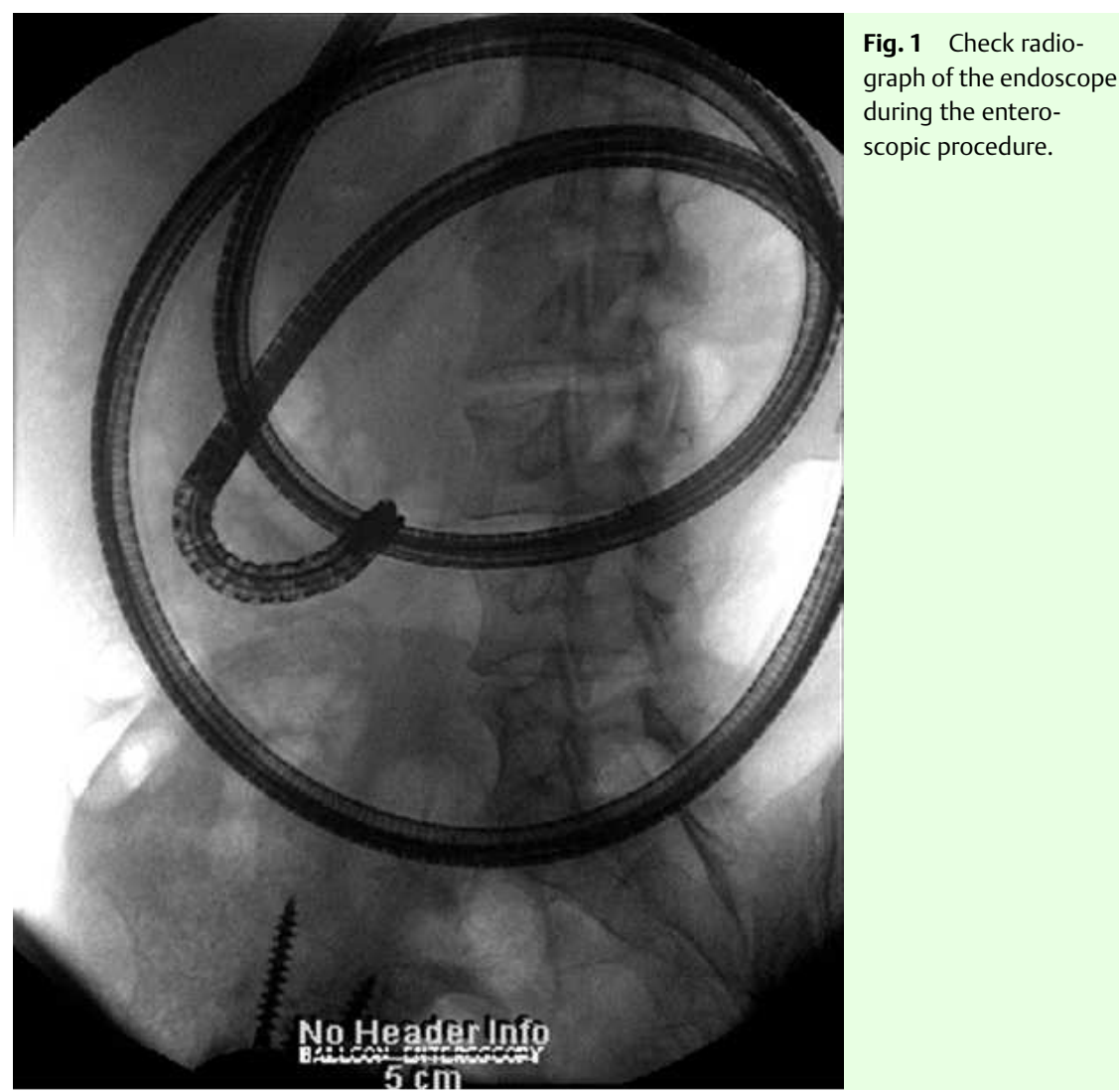

In the case illustrated here, the portal of entry was mucosal trauma during the enteroscopic procedure. The risk of bacterial translocation following SBE in patients with portal hypertension should be highlighted, and thus antibiotic prophylaxis considered prior to SBE.

\section{Endoscopy_UCTN_Code_CPL_1AI_2AD}

\section{J. Austin, A. L. Rivett, S. Anderson}

Department of Gastroenterology,

St Thomas' Hospital, London, UK

\section{References}

1 Vargo JJ, Upchurch B, Dumot JA et al. Clinical utility of the Olympus single balloon enteroscope: the initial US experience. Gastrointest Endosc 2007; 65: AB90

2 Mensink P, Haringsma J, Kucharzik TF et al. Complications of double balloon enteroscopy: a multicenter survey. Gastrointest Endosc 2007; 39: 613-615

3 Skogberg K, Simonen H, Renkonen OV, Valtonen $V V$. Beta-haemolytic group A, B, C and G streptococcal septicaemia: a clinical study. Scand J Infect Dis 1988; 20: 119-125
4 Ruoff KL. Streptococcus anginosus ("Streptococcus milleri"): the unrecognized pathogen. Clin Microbiol Rev 1988; 1: 102 - 108

5 Djupesland P, Solgaard T, Mair IWS. Cerebral abscess complicating dilatation of esophageal stricture. Eur Arch Otorhinolaryngol 1991; 248: 308 - 310

Bibliography

DOI $10.1055 / \mathrm{s}-2008-1077544$

Endoscopy 2008; 40: E246

(c) Georg Thieme Verlag KG Stuttgart · New York ISSN 0013-726X

Corresponding author

M. J. Austin, MRCP (UK)

Department of Gastroenterology

St Thomas' Hospital

London

SE1 7EH

UK

Fax: +44-207-1882484

mark.austin@gstt.nhs.uk 